\title{
Program Evaluation on General English Course: A Case Study at Tabriz University
}

\author{
Zohre Mohamadi \\ English Teaching Department, Islamic Azad University of Karaj, Karaj, Iran
}

\begin{abstract}
In the present study aims at evaluating general English program at Tabriz University, Iran. To this end, three questionnaires were designed in Likert scales which included needs analysis, materials evaluation from students' point of view and teacher analysis in which students provide their ideas about the agreement between their perceived needs, provided materials, and the methodology practiced in their classes. The data gathered for the purpose of data analysis. The data were analyzed both qualitatively and quantitatively in order to answer the research questions. Since the needs analysis was a complex task with various possibilities of the needs and contexts, questions tap different constructs. So In quantitative analysis, the descriptive statistics were used to calculate the frequency with which different choices of the questions in the questionnaires occur. To make more comprehensive picture, the data were analyzed qualitatively too. In qualitative analysis, students' answers to the questionnaires, their performance in the class and what the teachers observed in the class and students' personal and informal talks with the teachers and stakeholders were compared to find patterns of convergence and divergence in the data.
\end{abstract}

Index Terms - program evaluation, materials developments, needs analysis, teacher evaluation, and textbook analysis

\section{INTRODUCTION}

As one might expect, over the last 35 years a number of those involved in language planning have put forward their ideas about what might constitute a model of language policy and planning whereas others have contributed to understanding the discipline be concentrating on language planning goals. Kaplan and Baldauf (1997 cited in Hinkel 2005) have argued the ideas need to be framed within an ecological context, whereas Hornberger (1994 cited in Hinkel 2005) was the first to explicitly bring the model and goals strands together in a single framework. When thinking about the things that contribute to a model, both policy and planning components need to be considered as well as whether such policy and planning is or will be overt or cover in terms of the way it is decided and put out into action. In addition, when language policy and planning is undertaken, there is a significant underlying historical and social component that helped to frame ongoing.

\section{BACKGROUND AND PURPOSES}

Evaluation focuses primarily on the institutional issues (institution is defined broadly as everything from the class, to the school and the society in which they are located) and, in particular, is motivated to a large extent by accountability requirements (for example, society's taxpayers demanding evidence that state school funding is being used efficiently and wisely). Purposes for evaluation are of two general types of motivation; administrative and instructional. Administrative purposes include making decisions about how to select or place individuals within language programs and how to organize or develop those programs. Instructional purposes include decisions about what individuals have achieved, as well as what they still need to learn, and how well components of the language programs are working.

A distinction that is sometimes made along these lines is the difference between summative and formative evaluation. In general, summative can be seen to correspond to administrative purposes. It is concerned with decisions about whether an individual student is ready for a particular level of program (or ready for entry of exemption) or not, whether the program is successful or not. Formative refers to decisions about assessing the process and ongoing needs of individuals in a language program or the ongoing nature of the program (which components are working, which need to be changed). Of course, summative and formative overlap, as do administrative and instructional. When we gather evidence to decide whether a program is successful or not (summative, administrative), we are usually interested in the possibility of making changes to improve it (formative, instructional). There are times, however, when one decision type or the other is the focus and the primary motivation for our evaluation efforts. Formative evaluation occurs while the program is being implemented and developed. The goal is to recommend changes for improving it, and, towards this end, it focuses on the program processes.

Typically the outcome of a formative evaluation is numerous small-scale recommendations for change. Summative evaluation occurs at the end of a program's natural term or cycle. The goal is to make an ultimate judgment about the program's worth, whether it has succeeded in meeting its objective or not. Typically the outcome of a summative evaluation id a formal report to be used in large scale decisions such as whether to continue funding the program or not. 
Most people involved in language program administration and evaluation would say that few, if any, programs are ever entirely completed in terms of development, making summative evaluation difficult in its extreme form. In fact, most evaluations represent a combination of formative and summative. If we are interested in judging the ultimate worth of a program, we are usually open to explanations of why it is or is not working, and recommendations for improvement. Lynch (2003) also discusses this formative versus summative distinction as confirming versus innovative; that is sometimes our motivation is to decide whether or not our current practice (program) is doing what it should; at other times our motivation is to bring about innovation or change in those practices.

When a strict summative evaluation is called for, Brown (1989 cited in Lynch, 2003) points out it is best to avoid doing it in crisis mode. One way around this problem is to make formative evaluation an ongoing part of program process, so that the necessary information and procedures for gathering it are available without disruption (or at least with minimal disruption) to the normal running of the program. This leads to another way of looking at evaluation purposes; responding to external mandates and demands versus internal motivations for evaluation. Often, the purpose of an externally motivated evaluation is to arrive at a summative or combined summative and formative judgment of the program by looking at the material indicators, for example, the program's resources (books, professional credentials of staff, classroom space) as the primary indicators of its worth. Besides looking at the material indictors or other program products, another purpose for evaluation is to examine how the materials are used and the products are achieved. The major focus in this project is to understand program process.

Materials development is both a field of study and a practical undertaking (Cunningworth, 1995). As a field it studies the principles and procedures of the design, implementation and evaluation of language teaching materials as an undertaking it involves the production, evaluation and adaptation of language teaching materials, by teachers for their own classroom and by materials writers. These two aspects of material development are interactive in that the theoretical studies inform and are informed by the development and the use of classroom materials (Tomlinson, 2003). Materials can include anything which can be used to facilitate the learning of a language. They can be linguistic, visual, auditory and etc. they can be instructional, experiential, elicitative or exploratory. It means that they can inform learners about language for themselves. Learners' needs and wants should derive the materials. These needs and wants are not irreconcilable and can be satisfied by localized projects which consult learners, teachers, and administrators before, during and after the materials.

Pre-use evaluation involves making predictions about the potential value of materials for their users. Often pre -use evaluation is impressionistic and consists of a teacher flicking through a book to gain a quick impression of its potential value. Making an evaluation criterion referenced can reduce subjectivity and can certainly help to make an evaluation more principled, rigorous, systematic and reliable. This is especially true if more than two evaluators conduct the evaluation independently and then the average their conclusion.

Whilst- use evaluation involves measuring the value of materials whilst using them or whist observing them being used. It can be more objective and reliable than pre-use evaluation as it makes use of measurement rather than prediction. However it is limited to measuring what is observable and cannot claim to measure what is happening in the learners' brains. It can measure short term memory through observing learner performance on exercises but it cannot measure durable and effective learning because of the delayed effect of instruction.

Post -use evaluation is probably the most valuable but the least administered type of evaluation as it can measure the actual effects of the materials on the users. It can measure the short-term effect as regards motivation, impact, achievability, instant and application. In other words, it can measure the actual outcomes of the use of the materials and thus provide the data on which reliable decisions about the use, adaptation or replacement of the materials can be made. The main problem is that it takes time and expertise to measure post-use effects reliably.

Current language programs primarily signify the very specific needs for which the learners are motivated to learn English. Therefore, the identification of these needs is the most critical step to develop materials or for preparing the learners for the related activities they need to perform in future. In fact, needs analysis help material developers and syllabus designers to select appropriate ways to bridge the gap between the learners' present command of English with that of they need to use in future and the means and the learning conditions influence their movement through this procedure. Needs analysis is described by Jordan (1997) as the process of determining the needs for which a learner or group of learners requires a language and arranging the needs according to priorities.

Although language planning and materials development have been around for many centuries undergoing various changes over centuries, they are oversimplified on a number of grounds. There has been a desire to over flood the market with all fit materials development and curriculum development in turn with little or no awareness of the kind of impact they may have on teaching and learning a language and objective achievements. Underlying any attempts in successful language planning and program, curriculum development, materials development is a focus on evaluation (Mukundun \& Nimehchisalem, 2011). The present study aims to evaluate the general English language program at Tabriz University to investigate the efficiency of the components of the program in goal achievement.

\section{Research Question}

Considering the points mentioned above the following research questions are set:

1. Does Tabriz University general English language program meet students' present and future needs efficiently? 
2. Are Tabriz University's general English language program materials efficiently in line with the students' present and future needs considering students point of view and that of the teachers?

3. Is Tabriz University's general English language program methodology with the focus on the teacher as the important agent efficiently in line with the students' present and future needs?

\section{METHOD}

\section{A. Participants}

The participants in the present study are 536 non-native male and female students from different majors who receive the same General English language course at Tabriz University. They are all between 18 to 30 years old whose L1 is Persian. The participants are approximately at the same level of English language proficiency with no or very little English language learning experience.

\section{B. Instrumentation}

Questionnaire. After deciding on the questions and classification of the questions according to the frameworks mentioned in the literature by different scholars namely Hutchinson and Water (1987), Robinson (1991), Jordan (1997), and Flowerdew and Peacock (2001), the questions were designed in the form of three questionnaires.

The first questionnaire was designed as need analysis questionnaire which had 5 parts. Part one is descriptor and related to learners' general characteristics. Part 2 is related to learners' target language needs which are validated according the theoretical framework in literature. Part 3 is designed on the bases of learners' present needs which are cross validated by different scholars' views. Part 4 is designed on the base of learners ' preferences and strategy use. Part 5 is designed on the base of learners learning needs on the base of the set of questions proposed by Hutchinson and Water (1987) to identify learners learning needs. The questions were appraised and evaluated by the professor. Then the questions were translated to Farsi and reviewed by a colleague to resolve any source of miscomprehension. Final draft was prepared and administered to participants. Samples were selected by convenient sampling procedure and the questionnaire is conducted at one setting. The questionnaire is in fixed format restricted response.

The second questionnaire was designed to evaluate the textbook students were studying during the semesters. This questionnaire was designed to evaluate the textbooks from the participants' point of view.

The third questionnaire was designed to evaluate the methodology used by teachers to teach the course. Participants were supposed to evaluate if the methodology adapted by the teachers were on line with their needs.

\section{Design}

Participants were informed about the purpose of the project and they are made sure about the confidentiality of the answers. Questionnaires were handed to the participants in single session and the teachers were asked to help students in the case of miss understanding. The data were gathered for the purpose of data analysis.

\section{DATA ANALYSis}

The data were analyzed both qualitatively and quantitatively in order to answer the research questions. Since the needs analysis is a complex task with various possibilities of the needs and contexts, questions tap different constructs. So In qualitative analysis, the descriptive statistics was used to calculate the frequency with which different choices of the questions in the questionnaires occur. To make more comprehensive picture the data are analyzed qualitatively too. In qualitative analysis, students' answers to the questionnaires and their performance in the class and what the teachers observed in the class and students' personal and informal talks with the teachers and stakeholders are compared to find patterns of convergence and divergence in the data.

\section{RESUlT AND DISCUSSION}

\section{A. Needs Analysis}

\section{Research Question I}

First, the needs analysis questionnaire was evaluated to answer the first research question which is if Tabriz University' general English language program meets students' present and future needs efficiently. The best item to start with in this questionnaire is motivation which was designed in questions 5, 20, 25. In question 5 which is about the necessity of learning a foreign language as a requirement in order to graduate, $81 \%$ of the participants selected the first and second choice which say it is necessary to learn a foreign language as a requirement in order to graduate. Question 20 is related to the required amount of time that participants think should be allocate to English learning in their academic schedule. $90 \%$ of the participants selected the first and second choices which say more than 2 or 4 hours are needed to spend on English language in their general English language education program. The next question which was designed to tap student's degree of motivation in English language leaning is question 25which asks about the reasons for learning English language. Only 14\% of the participants selected the first choice which says the reason why participants learn English is that it is obligatory. 82\% of the participants selected other choices which say the reasons 
for learning English are related to the increase in the social status, better job and better financial conditions and promotions in their career.

TABLE 1.

DESCRIPTIVE STATISTICS ON QUESTION 5

\begin{tabular}{llllll} 
& & Frequency & Percent & Valid Percent & Cumulative Percent \\
\hline \multirow{4}{*}{ Valid } & choice 1 & 323 & 60.3 & 60.6 & 60.6 \\
\cline { 2 - 6 } & choice 2 & 116 & 21.6 & 21.8 & 82.4 \\
\cline { 2 - 6 } & choice 3 & 79 & 14.7 & 14.8 & 97.2 \\
\cline { 2 - 6 } & choice 4 & 15 & 2.8 & 2.8 & 100.0 \\
\cline { 2 - 6 } & Total & 533 & 99.4 & 100.0 & \\
\hline Missing & System & 3 & .6 & & \\
\hline Total & 536 & 100.0 & &
\end{tabular}

TABLE 2.

\begin{tabular}{llllll}
\multicolumn{5}{c}{} & \multicolumn{5}{c}{ DESCRIPTIVE STATISTICS ON QUESTION 20 } & \\
& & Frequency & Percent & Valid Percent & Cumulative Percent \\
\hline \multirow{4}{*}{ Valid } & choice 1 & 249 & 46.5 & 47.5 & 47.5 \\
\cline { 2 - 6 } & choice 2 & 173 & 32.3 & 33.0 & 80.5 \\
\cline { 2 - 6 } & choice 3 & 52 & 9.7 & 9.9 & 90.5 \\
\cline { 2 - 6 } & choice 4 & 50 & 9.3 & 9.5 & 100.0 \\
\cline { 2 - 6 } & Total & 524 & 97.8 & 100.0 & \\
\hline Missing & System & 12 & 2.2 & & \\
\hline Total & 536 & 100.0 & &
\end{tabular}

TABLE 3.

DESCRIPTIVE STATISTICS ON QUESTION 25

\begin{tabular}{|c|c|c|c|c|c|}
\hline & & Frequency & Percent & Valid Percent & Cumulative Percent \\
\hline \multirow{5}{*}{ Valid } & choice 1 & 80 & 14.9 & 15.2 & 15.2 \\
\hline & choice 2 & 315 & 58.8 & 59.7 & 74.8 \\
\hline & choice 3 & 36 & 6.7 & 6.8 & 81.6 \\
\hline & choice 4 & 97 & 18.1 & 18.4 & 100.0 \\
\hline & Total & 528 & 98.5 & 100.0 & \\
\hline Missing & System & 8 & 1.5 & & \\
\hline Total & & 536 & 100.0 & & \\
\hline
\end{tabular}

Now, whether this high motivation is paid attention to in educational system of Tabriz University should be evaluated. To answer this question, the researcher used several options. After motivation, the objectives that participants plan to achieve by learning English are important since the researcher tried to investigate if these objectives could be met by current educational system. This construct was taped in questions 6, 7, 12 .

In question 6 which is about the participants' objective in learning English, 45\% of the participants selected the first choice which says the objective participants pursue is communication with other English speakers whereas other choices which are personal interest, meeting job and education requirements have lower frequencies.

TABLE 4.

DESCRIPTIVE STATISTICS ON QUESTION 6

\begin{tabular}{|c|c|c|c|c|c|}
\hline & & & & & \\
\hline & & Frequency & Percent & Valid Percent & Cumulative Percent \\
\hline & choice 1 & 235 & 43.8 & 45.0 & 45.0 \\
\hline & choice 2 & 65 & 12.1 & 12.5 & 57.5 \\
\hline Valid & choice 3 & 83 & 15.5 & 15.9 & 73.4 \\
\hline & choice 4 & 139 & 25.9 & 26.6 & 100.0 \\
\hline & Total & 522 & 97.4 & 100.0 & \\
\hline Missing & System & 14 & 2.6 & & \\
\hline Total & & 536 & 100.0 & & \\
\hline
\end{tabular}

Question 7 is also related to the objectives. In this question, 55\% of the participants selected the first choice which says the main objective is speaking in English whereas the rest of the choices which are writing, reading and listening have lower frequencies of $7 \%, 21 \%$ and $15 \%$ respectively.

TABLE 5.

DESCRIPTIVE STATISTICS ON QUESTION 7

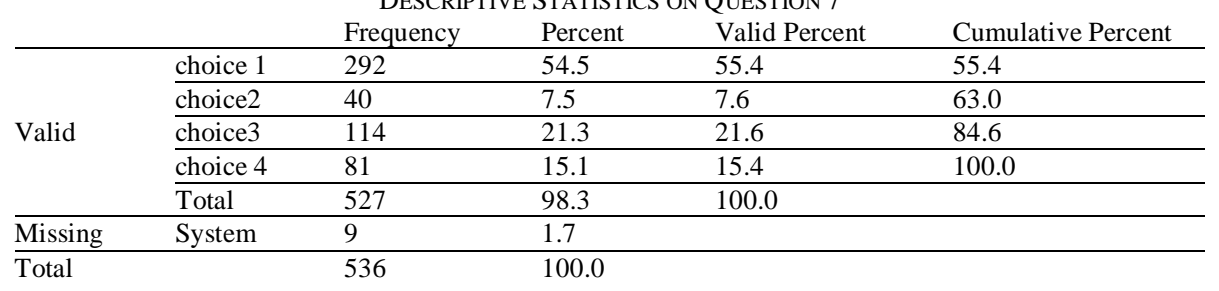


Question 12 is also designed to check participants' objectives. In this question, 54\% of the participants selected the second choice which is improving speaking skills as their main objective. Other choices which are related to improving writing, reading and translation have lower frequency

TABLE 6.

DESCRIPTIVE STATISTICS ON QUESTION 12

\begin{tabular}{|c|c|c|c|c|c|}
\hline & & Frequency & Percent & Valid Percent & Cumulative Percent \\
\hline \multirow{6}{*}{ Valid } & choice 1 & 34 & 6.3 & 6.5 & 6.5 \\
\hline & choice 2 & 284 & 53.0 & 54.2 & 60.7 \\
\hline & choice 3 & 47 & 8.8 & 9.0 & 69.7 \\
\hline & choice 4 & 115 & 21.5 & 21.9 & 91.6 \\
\hline & choice 5 & 44 & 8.2 & 8.4 & 100.0 \\
\hline & Total & 524 & 97.8 & 100.0 & \\
\hline Missing & System & 12 & 2.2 & & \\
\hline Total & & 536 & 100.0 & & \\
\hline
\end{tabular}

The researcher reached to this conclusion that the main objective of the students for learning English is communicating orally with the world around. The researcher aims at evaluating if the teachers and materials help participants to reach their objective or not in later section.

The next option in this needs analysis was the participants' current proficiency level. This option is designed in questions $11,13,14,15$, and 16. In question is about their strength in four language skills. In question $11,41 \%$ of the participants selected reading as the skill at which there were competent and the other skills like listening and speaking have $28 \%$ and $15 \%$ frequency.

TABLE 7.

DESCRIPTIVE STATISTICS ON QUESTION 11

\begin{tabular}{|c|c|c|c|c|c|}
\hline & & Frequency & Percent & Valid Percent & Cumulative Percent \\
\hline \multirow{7}{*}{ Valid } & choice 1 & 83 & 15.5 & 15.7 & 15.7 \\
\hline & choice 2 & 72 & 13.4 & 13.6 & 29.4 \\
\hline & choice 3 & 219 & 40.9 & 41.5 & 70.8 \\
\hline & choice 4 & 150 & 28.0 & 28.4 & 99.2 \\
\hline & 5.00 & 3 & .6 & .6 & 99.8 \\
\hline & 33.00 & 1 & .2 & .2 & 100.0 \\
\hline & Total & 528 & 98.5 & 100.0 & \\
\hline Missing & System & 8 & 1.5 & & \\
\hline Total & & 536 & 100.0 & & \\
\hline
\end{tabular}

Question 13 is related to the participants' current level of listening skills. $47 \%$ of the participants declared that they are weak at listening skills.

TABLE 13.

\begin{tabular}{|c|c|c|c|c|c|}
\hline & & DESCRIP & STATISTIC & QUESTION 13 & \\
\hline & & Frequency & Percent & Valid Percent & Cumulative Percent \\
\hline & choice 1 & 51 & 9.5 & 9.6 & 9.6 \\
\hline & choice 2 & 111 & 20.7 & 20.9 & 30.5 \\
\hline & choice 3 & 118 & 22.0 & 22.2 & 52.6 \\
\hline Valid & choice 4 & 250 & 46.6 & 47.0 & 99.6 \\
\hline & 5.00 & 1 & .2 & .2 & 99.8 \\
\hline & 400.00 & 1 & .2 & .2 & 100.0 \\
\hline & Total & 532 & 99.3 & 100.0 & \\
\hline Missing & System & 4 & .7 & & \\
\hline Total & & 536 & 100.0 & & \\
\hline
\end{tabular}

It can be noticed that whereas participants have considered speaking and oral communication as their main objectives, they are very weak at these skills. In relation to their objective, having this weak level of proficiency in speaking and listening may cause problems in reaching their objectives.

Question 14 is related to the participants' current writing skills. Only 9\% of the participants evaluated themselves as weak whereas $39 \%$ and $34 \%$ of the participants evaluated their writing skills as intermediate or advance respectively. Considering these percentages in relation with participants' objective which is oral communication, it seems the current English learning program is not efficient. 
TABLE 14.

\begin{tabular}{llllll}
\multicolumn{5}{c}{} & \multicolumn{5}{c}{ DESCRIPTIVE STATISTICS ON QUESTION 14 } \\
& Frequency & Percent & Valid Percent & Cumulative Percent \\
\hline \multirow{3}{*}{ Valid } & choice1 & 73 & 13.6 & 14.1 & 14.1 \\
\cline { 2 - 6 } & choice 2 & 210 & 39.2 & 40.7 & 54.8 \\
\cline { 2 - 6 } & choice 4 & 182 & 34.0 & 35.3 & 90.1 \\
\cline { 2 - 6 } & Thoice 4 & 51 & 5.5 & 9.9 & 100.0 \\
\hline Missing & System & 20 & 96.3 & 100.0 & \\
\hline Total & 536 & 3.7 & &
\end{tabular}

Question 15 is about participants' current speaking ability. 37\% of the participants evaluated their speaking ability as average and $33 \%$ as weak whereas very good and good rates have the frequency of $6 \%$ and $19 \%$. Considering the participants objective which is oral communication, this frequency is of less significance and this shows that English education system and at broader scope English education programming and policy are not in match with participants needs and current proficiency level.

TABLE 15.

DESCRIPTIVE STATISTICS ON QUESTION 15

\begin{tabular}{llllll} 
& & Frequency & Percent & Valid Percent & Cumulative Percent \\
\hline \multirow{4}{*}{ Valid } & choice 1 & 32 & 6.0 & 6.3 & 6.3 \\
\cline { 2 - 6 } & choice 2 & 101 & 18.8 & 19.8 & 26.1 \\
\cline { 2 - 6 } & choice 3 & 200 & 37.3 & 39.2 & 65.3 \\
\cline { 2 - 6 } & Shoice 4 & 177 & 33.0 & 34.7 & 100.0 \\
\hline Missing & System & 510 & 95.1 & 100.0 & \\
\hline Total & 26 & 4.9 & &
\end{tabular}

In relation to the above mentioned points, question 26 is related to the participants' English learning experiences. $61 \%$ of the participants selected choice 3 which says they have little English learning experience. Therefore, the current educational system should take responsibilities in providing a better educational medium on the basis of participants' needs.

TABLE 16.

\begin{tabular}{llllll}
\multicolumn{5}{c}{} & \multicolumn{5}{c}{ DESCRIPTIVE STATISTICS ON QUESTION 26 } & \\
& & Frequency & Percent & Valid Percent & Cumulative Percent \\
\hline \multirow{3}{*}{ Valid } & choice 1 & 34 & 6.3 & 6.4 & 6.4 \\
\cline { 2 - 6 } & choice 2 & 134 & 25.0 & 25.3 & 31.8 \\
\cline { 2 - 6 } & choice 3 & 327 & 61.0 & 61.8 & 93.6 \\
\cline { 2 - 6 } & Thoice 4 & 34 & 6.3 & 6.4 & 100.0 \\
\hline Total & 529 & 98.7 & 100.0 & \\
\hline Missing & System & 7 & 1.3 & & \\
\hline Total & 536 & 100.0 & &
\end{tabular}

The next option is related to the methods of evaluating students' progress which is designed in question 21 and 23 . In question 21 which is about the kind of learning strategies desired by the participants, $50 \%$ and $24 \%$ of the participants selected group work and pair work as their desire strategies whereas only $23 \%$ selected individual leaning. Creating opportunities for cooperative learning is desirable. To see if this desired learning strategy is paid attention to by the teaching methodology or materials, the second and their questioner data should be analyzed.

TABLE 17.

\begin{tabular}{llllll}
\multicolumn{5}{c}{} & \multicolumn{5}{c}{ DeSCRIPTIVE STATISTICS ON QUESTION 21 } & \\
& & Frequency & Percent & Valid Percent & Cumulative Percent \\
\hline \multirow{4}{*}{ Valid } & choice 1 & 124 & 23.1 & 23.4 & 23.4 \\
\cline { 2 - 6 } & choice 2 & 133 & 24.8 & 25.1 & 48.5 \\
\cline { 2 - 6 } & choice 3 & 270 & 50.4 & 50.9 & 99.4 \\
\cline { 2 - 6 } & choice 4 & 3 & .6 & .6 & 100.0 \\
\cline { 2 - 6 } & Total & 530 & 98.9 & 100.0 & \\
\hline Missing & System & 6 & 1.1 & & \\
\hline Total & 536 & 100.0 & &
\end{tabular}

In Question 23 which is about the method favored by participants to know about their progress, 56\% of the participants declared the use of English in daily activities as the best way to know if they have progress or not whereas the other choice that highlighted the role of teachers in this evaluation have lower frequency. For example, written examination has $19 \%$ and oral examination prepared by the teacher has $14 \%$ of frequency. The point that less active role given to the teacher by participants in evaluating learning may show participants have a great tendency for taking more responsibility in their own learning which will be crossed check with the results of the other questionnaires. 
TABLE 18.

\begin{tabular}{llllll}
\multicolumn{5}{c}{} & \multicolumn{5}{c}{ DESCRIPTIVE STATISTICS ON QUESTION 23 } & \\
& & Frequency & Percent & Valid Percent & Cumulative Percent \\
\hline \multirow{4}{*}{ Valid } & choice 1 & 103 & 19.2 & 19.5 & 19.5 \\
\cline { 2 - 6 } & choice 2 & 78 & 14.6 & 14.8 & 34.3 \\
\cline { 2 - 6 } & choice 3 & 49 & 9.1 & 9.3 & 43.6 \\
\cline { 2 - 6 } & Shoice 4 & 296 & 55.2 & 56.2 & 99.8 \\
\cline { 2 - 6 } & Total & 527 & .2 & 100.0 & \\
\hline Missing & System & 9 & 98.3 & 100.0 \\
\hline Total & 536 & 1.7 & &
\end{tabular}

The other option in needs analysis questionnaire is providing opportunities for the participants to use what they learned in the class in out of class contexts. Since participants declared they have very limited English learning experience (question 26) and since they have a great motivation for English language learning (question 5, 7, 22), creating opportunities for participants to use the learned language is of great significance. This point is designed by question 28. In this question, $72 \%$ of the participants claimed that the only learning opportunity they have out of the classroom is limited their doing their homework and reading their lessons, whereas only $3 \%$ and $12 \%$ of the participants have discussion opportunities on the learned material out of the class context. This shows that the focus of the English educational system is on writing and reading whereas most of the participants considered oral communication as their main objective. It is definitely it is the time for a change so that a match between participants needs and what is prescribed in advance, between what is actually happening and what is appropriate.

TABLE 19

\begin{tabular}{llllll}
\multicolumn{5}{c}{} & \multicolumn{5}{c}{ DeSCRIPTIVE STATISTICS ON QUESTION 28 } & \\
& & Frequency & Percent & Valid Percent & Cumulative Percent \\
\hline \multirow{3}{*}{ Valid } & choice 1 & 20 & 3.7 & 4.0 & 4.0 \\
\cline { 2 - 6 } & choice 2 & 68 & 12.7 & 13.4 & 17.4 \\
\cline { 2 - 6 } & choice 3 & 365 & 68.1 & 72.1 & 89.5 \\
\cline { 2 - 6 } & choice 4 & 53 & 9.9 & 10.5 & 100.0 \\
\cline { 2 - 6 } & Total & 506 & 94.4 & 100.0 & \\
\hline Missing & System & 30 & 5.6 & & \\
\hline Total & 536 & 100.0 & &
\end{tabular}

\section{Discussion I}

Evaluation is basically a matching process; matching needs to available Solutions. The current program evaluation showed that there is a great discrepancy between what is needed and what already is available, between what is actually happening and what is appropriate.

As an answer to the first research question which is if Tabriz University' general English language program meets students' present and future needs efficiently, various options have been evaluated in the form of designed questions in the questionnaire.

The first option is about motivation. Having checked the designed question for this construct, the researcher made this conclusion that participants are very motivated students since the considered learning English as a necessary prerequisite of being graduated. They also requested more time to be allocated to their English course. Only few percentage of students considered learning English as an obligatory activity. They are instrumentally motivated to its great extent. Unfortunately, their motivation is not responded appropriately in their current general English course since there was no match between what was happening and what was appropriate.

This is quite obvious in studying the next option which was about participants' objective for learning English. Great percentage of participants considered oral communication as the main reason for learning English and speaking as their most required skill, this is totally in contrast with what they receive as their English education program. Great percentages of participants claim that they are good at reading whereas their speaking and listening are weak. This shows that the current English program focused on writing and reading and now it is a time for a shift to speaking and listening skills which are not only are required by the participants to reach their objective which is oral communication but also they are very week at. Considering the participants objective which is oral communication, this shows that English education system and at broader scope English education programming and policy are not in match with participants needs and current proficiency level.

The other option in needs analysis questionnaire is providing opportunities for the participants to use what they learned in the class in out of class contexts. Since participants declared they have very limited English learning experience (question 26) and since they have a great motivation for English language learning (question 5, 7, 22), creating opportunities for participants to use the learned language is of great significance

\section{B. Textbook Evaluation}

\section{Research Question II}


To answer the second research question which is if Tabriz University's general English language program materials are efficiently in line with the students' present and future needs considering students point of view and that of the teachers, the second questionnaire which is textbook evaluation questionnaire was used.

The first construct in this questionnaire is about participants' motivation. This construct had high frequency in needs analysis questionnaire meaning that participants are highly motivated learners. The challenging point is if this motivation is responded in textbook participants study. This point is designed in questions 2, 4, 9. In question 2, 4 and 9 only $16 \%, 19 \%$ and $13 \%$ of the participants respectively consider the textbooks as motivational. This shows that high motivation on the side of participants is not responded by the textbooks.

TABLE 20.

DESCRIPTIVE STATISTICS ON QUESTION 2

\begin{tabular}{llllll} 
& \multicolumn{5}{c}{ DESCRIPTIVE STATISTICS ON QUESTION 2 } \\
& Frequency & Percent & Valid Percent & Cumulative Percent \\
\hline \multirow{3}{*}{ Valid } & no & 201 & 32.1 & 32.2 & 32.2 \\
\cline { 2 - 6 } & to some extent & 318 & 50.8 & 51.0 & 83.2 \\
\cline { 2 - 6 } & yes & 105 & 16.8 & 16.8 & 100.0 \\
\cline { 2 - 6 } & Total & 624 & 99.7 & 100.0 & \\
\hline Missing & System & 2 & .3 & &
\end{tabular}

TABLE 21.

DESCRIPTIVE STATISTICS ON QUESTION 4

\begin{tabular}{|c|c|c|c|c|c|}
\hline & & Frequency & Percent & Valid Percent & Cumulative Percent \\
\hline \multirow{5}{*}{ Valid } & no & 211 & 33.7 & 33.9 & 33.9 \\
\hline & to some extent & 288 & 46.0 & 46.3 & 80.2 \\
\hline & yes & 122 & 19.5 & 19.6 & 99.8 \\
\hline & 11.00 & 1 & .2 & .2 & 100.0 \\
\hline & Total & 622 & 99.4 & 100.0 & \\
\hline Missing & System & 4 & .6 & & \\
\hline Total & & 626 & 100.0 & & \\
\hline
\end{tabular}

TABLE 22.

DESCRIPTIVE STATISTICS ON QUESTION 9

\begin{tabular}{|c|c|c|c|c|c|}
\hline & & & & & \\
\hline & & Frequency & Percent & Valid Percent & Cumulative Percent \\
\hline \multirow{5}{*}{ Valid } & no & 268 & 42.8 & 43.2 & 43.2 \\
\hline & to some extent & 267 & 42.7 & 43.0 & 86.2 \\
\hline & yes & 85 & 13.6 & 13.7 & 99.8 \\
\hline & 22.00 & 1 & .2 & .2 & 100.0 \\
\hline & Total & 621 & 99.2 & 100.0 & \\
\hline Missing & System & 5 & .8 & & \\
\hline Total & & 626 & 100.0 & & \\
\hline
\end{tabular}

The next option in this questionnaire is related to the point if participants" needs are met in the textbooks or not. This point is designed by the questions 5 and 7 . In question 5 and 7 only $24 \%$ and $17 \%$ of the participants found textbooks in line with their needs. This low frequency shows that program developers should not prescribe any program in advance. The participant's needs should be taken into account.

TABLE 23.

DESCRIPTIVE STATISTICS ON QUESTION 5

\begin{tabular}{|c|c|c|c|c|c|}
\hline & & & ש & & \\
\hline & & Frequency & Percent & Valid Percent & Cumulative Percent \\
\hline & no & 174 & 27.8 & 27.9 & 27.9 \\
\hline & to some extent & 299 & 47.8 & 47.9 & 75.8 \\
\hline Valid & yes & 151 & 24.1 & 24.2 & 100.0 \\
\hline & Total & 624 & 99.7 & 100.0 & \\
\hline Missing & System & 2 & .3 & & \\
\hline Total & & 626 & 100.0 & & \\
\hline
\end{tabular}

TABLE 24.

DESCRIPTIVE STATISTICS ON QUESTION 7

\begin{tabular}{|c|c|c|c|c|c|}
\hline \multicolumn{6}{|c|}{ DESCRIPTIVE STATISTICS ON QUESTION 7} \\
\hline & & Frequency & Percent & Valid Percent & Cumulative Percent \\
\hline \multirow{4}{*}{ Valid } & no & 191 & 30.5 & 30.8 & 30.8 \\
\hline & to some extent & 321 & 51.3 & 51.8 & 82.6 \\
\hline & yes & 108 & 17.3 & 17.4 & 100.0 \\
\hline & Total & 620 & 99.0 & 100.0 & \\
\hline Missing & System & 6 & 1.0 & & \\
\hline Total & & 626 & 100.0 & & \\
\hline
\end{tabular}

The next option in this questionnaire is related to the activities and the way participants can get informed about their progress. This point is designed in question 10. This question asks if they can learn the martial by their own. Only $14 \%$ of the participants claim that the materials could be learned individually. Since in the needs analysis questionnaire it is understood that participants value pair work and group work, and since in the textbook questionnaire only $14 \%$ of 
students found textbooks in line with their preferred learning styles and the rest favored pair work and group work, materials developers need to provide a room for cooperative learning in textbooks.

\section{Discussion II}

Having analyzed the data on textbook questionnaire, the researcher found that participants' motivation was not responded by the textbooks as the participants consider their textbooks dissatisfactory. The other point about this analysis is related to whether participants' needs were met by the textbooks or not. Analysis of the data shows that textbooks are not in line with the participants' needs. The other point in this analysis is related to the activities and tasks on the books. Most of the activities and tasks are designed in such a way that they can be done individually whereas the preferred learning style by the students are pair work and group work. So materials should provide a room for cooperative learning.

A textbook doesn't exist for its own sake. The textbook fulfills a need, a purpose, it performs a function, conveys meaning. It is important for the developers of the materials to be aware of the needs, purpose, function and meaning so that appropriate and adequate resources may be employed to address and convey them. Textbook is structured along various levels to create meaning though the selection of resources from various options available to perform specific functions in specific contexts. ELT textbook is a communicative act; it has functions to be performed and meaning to be communicated by ELT textbook. The role of, materials in a language curriculum system is defined with respect to content (syllabus) and with respect to a learner and teacher roles. Instructional materials specify subject matter content; define the day to day objectives that collectively constitute the goals for the syllabus. The role of material reflects or must reflect decisions concerning its primarily goal and form, the relation the material holds to other sources of input and the abilities of the teachers. Thus, a textbook must take into account not just the leaning outcomes and the aims and objective defined by the syllabus, it must also informed by teacher needs and abilities and the context of teaching in the classroom. This context will shape its form or genre. The materials can be provided by making a workshop. Teachers were selected to provide a team of varying age, experiences and expertise. Some innovative approaches are demonstrated to extend the teachers repertoire of activity types and to stimulate thought and discussion about the principles of language learning. A flexible framework must be worked out to use in producing the materials and making some decisions together about the use of illustration, music and cassettes. Materials can be written and controlled in a small teams while small group of facilitators supported them and cross-checked with the syllabus. The last step is trailing, revisiting and editing.

\section{Teacher Analysis}

\section{Research Question III}

The third phase of this study is devoted to the evaluation of the methodology used to teach to the participants. The aim is to see if the method used is in line with participants' needs. The challenging point is to see if teachers responded to participants' needs in the form of teaching methodology and activities. This point is designed in questions $3,4,5,6,8$. In question 3, the participants were asked about how they evaluate their teachers' ability in conveying the intended meaning using relevant examples. $62 \%$ of the participants claim the teachers have high ability in conveying the intended meaning. The question is if having competent teachers is enough for success of any educational system.

Question 4 is related to the creation of group work and pair work opportunities. $51 \%$ of the participants claim that there was absence of group work. Since participants favored cooperative learning in the form of group work and pair work in the needs analysis, teachers should design these kinds of activities and include them in their lesson plan.

TABLE 25.

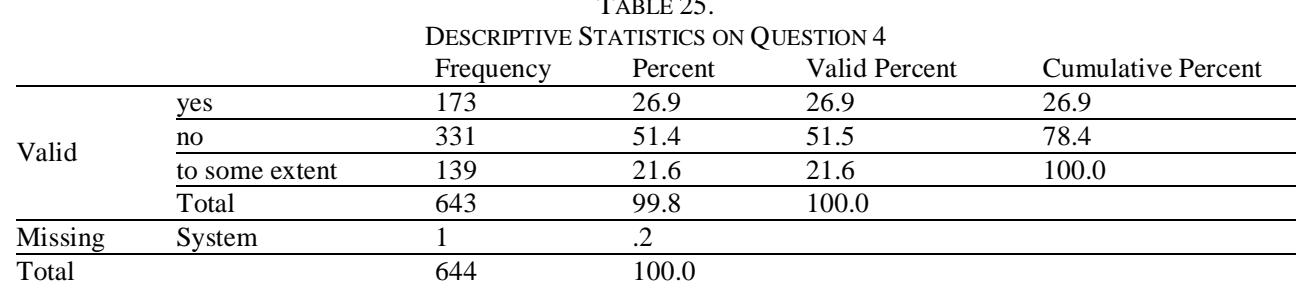

Question 8 is related to whether there is a match between participants' needs and the tasks and activities asked by the teacher. $44 \%$ of the participants claim that there is no match between what they need and the teachers provide them with in the form of activities and tasks and only $29 \%$ of the participants were satisfied by the classroom activities. 
TABLE 26.

\begin{tabular}{|c|c|c|c|c|c|}
\hline \multicolumn{6}{|c|}{ DESCRIPTIVE STATISTICS ON QUESTION 8} \\
\hline & & Frequency & Percent & Valid Percent & Cumulative Percent \\
\hline \multirow{5}{*}{ Valid } & yes & 191 & 29.7 & 29.7 & 29.7 \\
\hline & no & 289 & 44.9 & 44.9 & 74.7 \\
\hline & to some extent & 162 & 25.2 & 25.2 & 99.8 \\
\hline & 22.00 & 1 & .2 & .2 & 100.0 \\
\hline & Total & 643 & 99.8 & 100.0 & \\
\hline Missing & System & 1 & .2 & & \\
\hline Total & & 644 & 100.0 & & \\
\hline
\end{tabular}

Question 9 is related to the opportunities of the out of classroom context to use what was learned in the classes. Only $19 \%$ of the participants claim that they are provided with the opportunities to use the learned language in out of classroom context.

TABLE 27.

\begin{tabular}{|c|c|c|c|c|c|}
\hline \multicolumn{6}{|c|}{ DESCRIPTIVE STATISTICS ON QUESTION 9} \\
\hline & & Frequency & Percent & Valid Percent & Cumulative Percent \\
\hline \multirow{4}{*}{ Valid } & yes & 127 & 19.7 & 19.8 & 19.8 \\
\hline & no & 329 & 51.1 & 51.2 & 71.0 \\
\hline & to some extent & 186 & 28.9 & 29.0 & 100.0 \\
\hline & Total & 642 & 99.7 & 100.0 & \\
\hline Missing & System & 2 & .3 & & \\
\hline Total & & 644 & 100.0 & & \\
\hline
\end{tabular}

\section{Discussion III}

As it was the case with needs analysis and textbook evaluation, teacher analysis showed that there is a discrepancy between what the participants wanted and what the teacher provided in their classes through their lesson plans. Whereas participants desired group and pair work as their classroom activities, there was limited amount of cooperative learning since no opportunity was provided neither thorough teacher support nor through textbooks.

In the recent literature, the concept of the ideal teacher has some notoriety especially in relation to the native/ non native dichotomy. It is becoming a generally accepted view that outstanding teachers cannot be squeezed into any pigeonhole: all outstanding teachers are ideal in their own ways, and as such are different from each other. The concept of the ideal teacher resists clear cut definitions, because there are too many variables to consider. In order to get a better grasp of the ideal teacher we should suppose that other variables are kept constant momentarily, then language proficiency would be an important criterion. The trouble is that all things are never equal in the classroom, so the phrase the more proficient the more efficient is only partially valid. Certain factors which are as important as language proficiency, particularly relevant teaching qualifications and extent of one's teaching experience. There has been the danger of an automatic extrapolation from competent speaker to competent teacher based on linguistic grounds alone, without taking into consideration the criteria of cultural, social, and pedagogical appropriacy. Indeed, an issue waiting to be addressed is the complex relationship between the different aspects of teachers' classroom practice. Both native and non native teachers serve equally useful purposes in their own ways. Given a favorable mix, various forms of collaboration are possible, and learners can only gain from such cross-fertilization.

The teacher's role has grown tremendously. In the days when most research was experimental, investigations were typically conducted by outsiders to ensure objectivity in data collection and interpretation. Teachers were seen either as subjects in a particular study or as the implementers of the treatment in the experiment. Now, however, there is a much more inclusive view of teachers as partners in the research enterprise, working in collaboration with the researchers. The following roles of a teacher are provided by Harmer (2001).

When announcements need to be made, when order has to be restored, when explanations are given, or when the teacher is leading a question and answer session, the teacher acts as a controller. One of the most important roles that teachers have to perform is that of organizing students to do various activities. This often involves giving the students information, telling them how they are going to do the activity, putting them into pairs or groups, and finally closing things down when it is time to stop. In this case, the teachers act as an organizer.

One thing that students expect from their teachers is an indication of whether or not they are getting their English right. This is where the teachers act an assessor, offering feedback and correction and grading students in various ways. Students need to know how and for what they are being assessed. Sometimes when students are involved in a role-play activity, for example, they lose the thread of what is going on, or they are lost for words. They may not be quite sure how to proceed. In this case the teacher can act as a prompter.

There are many good reasons for teachers to take part in a discussion. They can enliven things from the inside instead of always having to prompt or organize from outside the group. When it goes well the students can enjoy having the teacher with them, and for the teacher, participating is often more instantly enjoyable as a resource. The danger of teachers as participants, of course, is that they may easily dominate the proceedings. Suppose that the students are involved in a piece of group writing, in such situation having the teacher take part, or try to control them, or even turn up to prompt them might be entirely unwelcome. However, the students may need their teachers as a resource. 
Teacher can also act as tutors working with the individuals or small groups. Pointing them in directions they have not yet thought of taking especially in longer projects.

Teachers can also observe students to see what they do so that they can give them useful group and individual feedback. Teachers do not only observe students to give feedback. They also watch in order to judge the success of the different materials and activities that they take into lessons so that they can, if necessary, make changes in the future. So teacher analysis involves analyzing all the effective roles that an efficient teacher may play within the constraints of the institution.

\section{CONCLUDing REMARK}

As the result of the study dictates, there is no match between participants' needs, textbooks provided for the participants and the kind of teaching they receive from their teachers. Therefore, general English course does not appear to have been developed based on contemporary ELT principles. The considerable budget that was dedicated to its development has interesting implications for language program developers and evaluators.

\section{APPENDIX I. NEEDS ANALYSIS}

*Answer the following questions.

Part1: General learner needs survey

Name

Age

Intended Occupation

Intended field of study

Purposes for English learning

People with whom you will interact

Other languages that you know

\section{Part 2: (Target language analysis)}

5. In your opinion, is it necessary to know a foreign language in order to graduate in your field?
a) Very much
b) not very much
c) a little
d) absolutely not

6. What is your main purpose in studying English?
a) communication
b) job
c) personal interest
d) your studies

7. Which skill do you think you need more in your future career? (Mark from the most important: 1, to the weakest: 4) Speaking

Writing

Reading

Listening

8. How will you use language in future?

a) Telephone or face to face communication b) written (reading and witting in English)

5. What type of text or discourse do you think you will use?
a) Academic text
b) every day conversation
c) lectures
d) technical manuals

9. Where will you use language?
a) Office
b) lecture theater
c) meetings
d) library

Part 3: (Present situation analysis)

10 In which skill do you think you are stronger at? (Mark from strongest: 1, to the weakest: 4)
1) Speaking
2) Writing
3) Reading
4) Listening

11. What kind of English course do you think you need more now? (Mark from the important 1, to the weakest 4.)
a) To improve writing skills
c) to improve reading skills
b) To improve speaking skills
d) to improve translation skills

10. How do you assess your proficiency in the following language skills?

12) Listening
a) very good
b) good
c) fair
d) weak
13) Writing
a) very good
b) good
c) fair
d) weak

14) Speaking

a) very good

b) good

c) fair

d) weak 

a) very good
b) good
c) fair
d) weak

16. Which type of speaking activity do you need more?
a) General conversation
B) group discussion
C) giving lectures

17. Which type of reading activity do you think will help you more to improve your reading skill?
a) reading journals
B) reading textbooks
C) reading texts with general subjects (news papers)

18. Which type of writing activity do you need more?
a) taking notes
B) writing reports
C) writing articles
b)writing projects

19. How many hours of instruction do you think are appropriate for your course?
a) 2 hours
b) 4 hours
c) 6 hours
d) more than 6 hours

Part 4: (strategy analysis)

20. How do you like learning?
a) individually
b) pair work
c) group work

21. What style of learning do you like more?
a) Memorizing
b) project based
c) listening and making notes

d) Writing and making notes

22. How do you like to find out how much your English is improving?

a) Written tasks set by the teachers

b) Oral language samples taken and assessed by the teacher

c) Checking your own progress by making tapes, listening and comparing

d) Seeing if you can use language you have learned in real life

23. How much are you interested in using subject specific texts than using general everyday used texts in order to improve your reading?
a) very much
b) much
c) not much

\section{Part 5: (Analyzing learning needs)}

24. Why are you taking the course?
a) compulsory
b) statues
c) money
d) promotion

25. How much experience do you have in learning English?
a) very much
b) much
c) a little
d) absolutely no experience

26. How much do you think that it is necessary for you to study general English before Specific English?
a) It is necessary
b) it is not necessary

27. How many opportunities do you have for out of class activities and practices?
a) Many
b) a few
c) absolutely no opportunity

28. What types of teaching and learning styles do you benefit more?
a) lecture type
b) discussion type
c) self study
d) project based

\section{ApPendix II. TeXtbook Evaluation}

This questionnaire is devised to evaluate the TEFL Program in Tabriz University. Your careful answers will be meaningful to the curriculum developers and TEFL program administrators. The information will be kept confidential and will be used just for evaluation purposes. Thank you for your cooperation.

Please check the box that best describes your view about the textbooks you are reading for the General English

\section{Course}

3 -1: from the highest degree of approval to the lowest

$$
3=\text { Completely } \quad 2=\text { Partly } \quad 1=\text { Not at all }
$$

1. Textbook evaluation 32

1. Are the topics appropriate, interesting, challenging, varied, culturally acceptable, and unlikely to date to the learners for whom the textbook is intended (urban rural environment; child or adult learners; male and/or female) 2. Is the ordering of materials done by topics, themes, and difficulty in a logical fashion?

3. Is the material accurate and up-to-date?

4. Are the activities appropriate for students?

5. Are the explanations understandable and usable for students?

6. Is the book sensitive to what students need in order to learn well?

7. Do textbooks encourage you to use language creatively?

8. Do textbooks provide you with suggestions and strategies for successful learning?

9. Can the materials be studied individually?

10. Do textbooks provide you with the opportunities to evaluate your learning like progress check, and self checks?

Please write about the points that are not considered in this questionnaire or the points that are considered but you want to elaborate on them. (Thanks for contribution in this study) 


\section{APPENDix III. Teacher EVALUation Questionnaire}

This questionnaire is devised to evaluate the TEFL Program in Tabriz University. Your careful answers will be meaningful to the curriculum developers and TEFL program administrators. The information will be kept confidential and will be used just for evaluation purposes. Thank you for your cooperation.

Please check the box that best describes your view about the teacher you have for the General English Course

\begin{tabular}{l} 
1. Do you think that your teacher needs to know the technical concepts of your major? \\
\hline 2. Do you think that your teacher is able to convey his intended meaning? \\
\hline 2. Does your teacher use suitable examples to convey his meaning? \\
\hline 4. Does you teacher provide some opportunities for group and pair work? \\
\hline 5. Does your teacher let you know about your progress during the semester? \\
\hline 6. Does your teacher ask for suggestion for better learning context? \\
\hline 7. Does your teacher use recent sources to teach you? \\
\hline 8. is there any match between your needs and textbooks' tasks? \\
9. Does your teacher provide some opportunities for the use of what you learner in out of classroom \\
context?
\end{tabular}

\section{REFERENCES}

[1] Cunningsworth, A. (1984). Evaluating and selecting EFL Teaching Materials. Heinnemann Educational Books. London.

[2] Cunningworth, A. (1995). Choosing your Textbook. Heinnemann Educational Books. London.

[3] Harmer, J. (2001). The Practice of English Language Teaching. Pearson Education. England.

[4] HInkel, Eli. (2005). Handbook of Research in Second Language Teaching and learning. Lawrence Erlbaum Associates, Inc., Publishers.

[5] Flowerdew, J \& Peacock, M. (2001). Research Perspective for EAP. Cambridge University Press. Cambridge.

[6] Hutchinson, T. \& Waters, A. (1993). English for Specific Purposes. Cambridge University Press. Cambridge.

[7] Jordan, P. R. (1997). English for Academic Purpose. Cambridge University Press. Cambridge.

[8] Lynch, K.B. (2003). Language Assessment and Program Evaluation. Edinburgh University Press. Edinburgh.

[9] Mukundum, J. \& Nimehchisalem, V. (2011). An evaluation of English teaching courseware in Malaysia. English Language Teaching 4(3), pp. 142-150.

[10] Robinson, P. (1991). ESP Today. Prgamon press. UK.

[11] Tomlinson, B. (2003). Developing Materials for Language Teaching. Continuum. London.

Zohre Mohamadi is a PhD candidate at Tarbiz University in teaching English as a foreign language. She accomplished her MA degree at Iran University of Science and Technology and her BA at Islamic Azad University. She has been the top student and top graduate student in all her educational programs.

She has published many papers in related journals and attended international conferences. She organized and presented different workshops on second language acquisition and learning. Her research interests are teacher education and training, materials development and teaching SPSS for research purposes. She teaches to both graduate and post graduate students.

Ms. Mohamadi is a faculty member of English teaching department at Islamic Azad University of Karaj, Karaj, Iran. She is also a member of TELLSI (Teaching English language and Literature Society of Iran). She has been a referee at Islamic Azad University conferences. 